Revue d'histoire de l'Amérique française

DEYUE D.HISTOIRE DE L'AMÉRIQUE FRANÇAISE

\title{
Réponse à la réplique de Pierre Poulin
}

\section{Henri Goulet}

Volume 50, numéro 4, printemps 1997

URI : https://id.erudit.org/iderudit/305612ar

DOI : https://doi.org/10.7202/305612ar

Aller au sommaire du numéro

Éditeur(s)

Institut d'histoire de l'Amérique française

ISSN

0035-2357 (imprimé)

1492-1383 (numérique)

Découvrir la revue

Citer ce compte rendu

Goulet, H. (1997). Compte rendu de [Réponse à la réplique de Pierre Poulin]. Revue d'histoire de l'Amérique française, 50(4), 633-633.

https://doi.org/10.7202/305612ar d'utilisation que vous pouvez consulter en ligne.

https://apropos.erudit.org/fr/usagers/politique-dutilisation/ 
Réponse de Henri Goulet à la réplique de Pierre Poulin.

La réplique de monsieur Poulin est doublement étonnante. Premièrement, parce qu'elle porte davantage sur ma prétendue mauvaise compréhension de la thèse de Ronald Rudin que sur ma critique de l'ouvrage de l'auteur lui-même. Pourtant, dans mon compte rendu, j'utilisais simplement Rudin pour corroborer la pertinence du questionnement sur le rôle économique des caisses tout au long de la période à l'étude, surtout en ce qui a trait à l'aide financière accordée aux organisations coopératives et aux consommateurs. Après avoir relu attentivement le chapitre 6 de l'ouvrage de monsieur Poulin, je me dois de réitérer ma position initiale: nulle part ne retrouve-t-on la démonstration qu'il y ait véritablement jonction entre le développement du nombre de caisses et celui de l'ensemble du mouvement coopératif. D'où mon interrogation sur l'utilité d'accorder une vingtaine de pages (p. 177-196) au développement de l'idéal coopératif chez les leaders nationalistes québécois ainsi qu'à la création d'une foule de coopératives au Québec, si ce n'est pour démontrer qu'il existe un lien entre ce vaste réseau et la force économique des 93,3 millions de dollars que représente l'actif de Desjardins en 1944 (p. 215). Bien que je sois conscient de l'existence de certaines études spécialisées sur cette question - dans le cadre d'un ouvrage historique portant spécifiquement sur l'évolution du Mouvement Desjardins -, le lecteur n'est-il pas justifié de réclamer l'amorce d'une démonstration chiffrée de cette collaboration?

Deuxièmement, monsieur Poulin ne semble pas avoir apprécié le fait que j'aie senti le besoin de souligner le caractère hagiographique de son ouvrage. Sans aucun rapport avec mon absence de goût pour les nuances, je croyais de mon devoir de relever le «discours agaçant» de l'historien qui glisse un peu trop généreusement dans l'histoire propagandiste de l'institution qu'il est en train d'analyser, comme en témoigne, à titre d'exemple seulement, cet extrait en conclusion du chapitre portant sur le rôle économique des caisses: "Si le système de crédit des caisses populaires montre quelques imperfections, il n'en demeure pas moins très efficace. [...] Les caisses ont permis à des centaines de paroisses de regrouper leur épargne et de l'employer à satisfaire des besoins de crédit locaux. [...] Les caisses ont ainsi procuré aux individus et aux collectivités locales un moyen d'accroître leur indépendance économique à partir de leurs propres ressources, d'exprimer leur solidarité et de se venir en aide. [...] Après 40 ans d'existence, les caisses avaient prouvé de façon éloquente que la petite épargne patiemment accumulée et bien gérée pouvait être à la source d'une véritable force économique.» (p. 262) Ce genre de discours représente une caractéristique importante traversant l'ensemble de l'ouvrage de monsieur Poulin et, pour cette raison, en toute objectivité, je croyais important de le souligner. J'insiste en terminant: le tome 2 de monsieur Poulin est très instructif sur l'évolution des structures du Mouvement Desjardins entre 1920 et 1944, mais, comme outil pour susciter un débat sur le rôle des caisses au Québec, il faudra encore attendre une analyse historique préconisant une approche différente de celle adoptée par l'historien de la Société historique Alphonse-Desjardins. 